\section{(6) OPEN ACCESS}

\title{
Patient-reported experience measure in sickle cell disease
}

\author{
Subarna Chakravorty, ${ }^{1,2}$ Amy Tallett, ${ }^{3}$ Cara Witwicki, ${ }^{3}$ Harriet Hay, ${ }_{1}^{3}$ \\ Catherine Mkandawire, ${ }^{4}$ Avanelle Ogundipe ${ }_{1}^{4}$ Patrick Ojeer, ${ }^{5}$ Antonia Whitaker, ${ }_{1}^{2}$ \\ Jessica Thompson, ${ }^{2}$ Stephen Sizmur, ${ }^{3}$ Ganesh Sathyamoorthy, ${ }^{6}$ John 0 Warner ${ }^{2,6}$
}

- Additional material is published online only. To view please visit the journal online (http://dx.doi.org/10.1136/ archdischild-2018-314955).

${ }^{1}$ Paediatric Haematology, King's College Hospital NHS Foundation Trust, London, UK ${ }^{2}$ Imperial College London, London, UK

${ }^{3}$ Picker, Oxford, UK ${ }^{4}$ Imperial College Healthcare NHS Trust, London, UK ${ }^{5}$ Sickle Cell Society, London, UK ${ }^{6}$ National Institute for Health Research Collaboration for Leadership in Applied Health Research and Care (NIHR (LAHRC) for North West London, London, UK

\section{Correspondence to} Dr Subarna Chakravorty, Department of Paediatric Haematology, King's College Hospital NHS Trust, London SE59RS, UK;

subarna.chakravorty@nhs.net

Received 17 February 2018

Revised 25 April 2018

Accepted 28 April 2018

Published Online First

4 August 2018

\section{Check for updates}

(C) Author(s) (or their employer(s)) 2018. Re-use permitted under CC BY-NC. No commercial re-use. See rights and permissions. Published by BMJ.

To cite: Chakravorty $S$,

Tallett A, Witwicki C, et al.

Arch Dis Child

2018;103:1104-1109.

\section{ABSTRACT}

Objectives To develop patient-reported experience measure surveys for patients with sickle cell disease (SCD) to understand their healthcare and lived experience in the UK and for their use in future to inform healthcare service development.

Design Picker methodology was used as follows:

(1) qualitative scoping by focus group discussions;

(2) questionnaire development through stakeholder consultations; (3) construct validation of questionnaires through cognitive testing; and (4) further assessment of construct validity by a nationwide pilot survey.

Setting Patients with SCD and their carers were eligible. Focus group discussions took place in nonhospital settings, arranged out of hours. Cognitive testing took place in specialist sickle cell clinics. The pilot survey was available to UK participants only and was administered through web-based questionnaires, face-to face completion and in sickle cell community events.

Participants Thirty-three patients and carers took part in the focus groups, 21 participants undertook cognitive testing and 722 respondents completed the pilot survey. Results Findings highlighted a widespread prevalence of poor knowledge about SCD among healthcare providers and the public. Poorer experience of care was present in the emergency setting compared with planned care, of which lack of timely provision of pain relief was of concern. Adolescents and young people reported significantly poorer experience of care in several domains compared with children or adults.

Conclusions The new surveys functioned well, with good evidence of validity, and were accessible to the SCD patient population, supporting their future use in assessing patient experience to inform service delivery and improvements in care quality.

\section{INTRODUCTION}

Sickle cell disease (SCD) is an inherited blood disorder characterised by episodic pain, chronic organ damage and reduction in life expectancy. Approximately 300 babies are identified annually by newborn screening in England. ${ }^{2}$ Despite being one of the most common significant genetically inherited conditions among newborns in England, SCD is unique in that it predominantly affects people of minority ethnic communities. ${ }^{3}$ There is a perceived association of stigma with the condition ${ }^{4}$ and the innately episodic nature of pain requiring frequent use of strong opioid-based analgesics ${ }^{5}$ renders this condition susceptible to prejudicial judgements and consequent poor patient experience of care. ${ }^{6}$

\section{What is already known on this topic?}

Sickle cell disease is one of the most common inherited disorders among newborns in England with significant health outcomes.

- However, evidence from the UK suggests prevalence of prejudicial treatment of this condition.

- This is likely to be due to innately episodic nature of the symptoms and requirement of opioid-based treatments leading to poor patient experience and outcome.

\section{What this study adds?}

- Over $50 \%$ of children experienced delays in receiving pain relief during vaso-occlusive episodes T

- he surveys have statistical validity for future use in assessing patient experience

Understanding patient views of their care experience is not optional, but essential to ensure effective delivery of healthcare. ${ }^{7}$ A better patient experience is associated with improved treatment adherence, better use of preventive services and healthcare utilisation. ${ }^{8}{ }^{9}$ Using patient experience to inform service development therefore is a core initiative in quality improvement projects within the National Health Service (NHS).

We therefore developed, piloted and assessed the validity of SCD-specific patient-reported experience measures (PREM). In this paper, we describe the PREM development process, explore its validity and outline the pilot findings on the healthcare and lived experience of patients with SCD. To our knowledge, this is the first ever report of implementing an SCD-specific PREM in the UK.

\section{METHODS}

Three sickle cell PREM questionnaires were developed using qualitative scoping by focus group discussions, followed by questionnaire development through stakeholder consultations. The questionnaires were subjected to construct validation through cognitive testing. Construct validity was further assessed by exploring responses and internal 


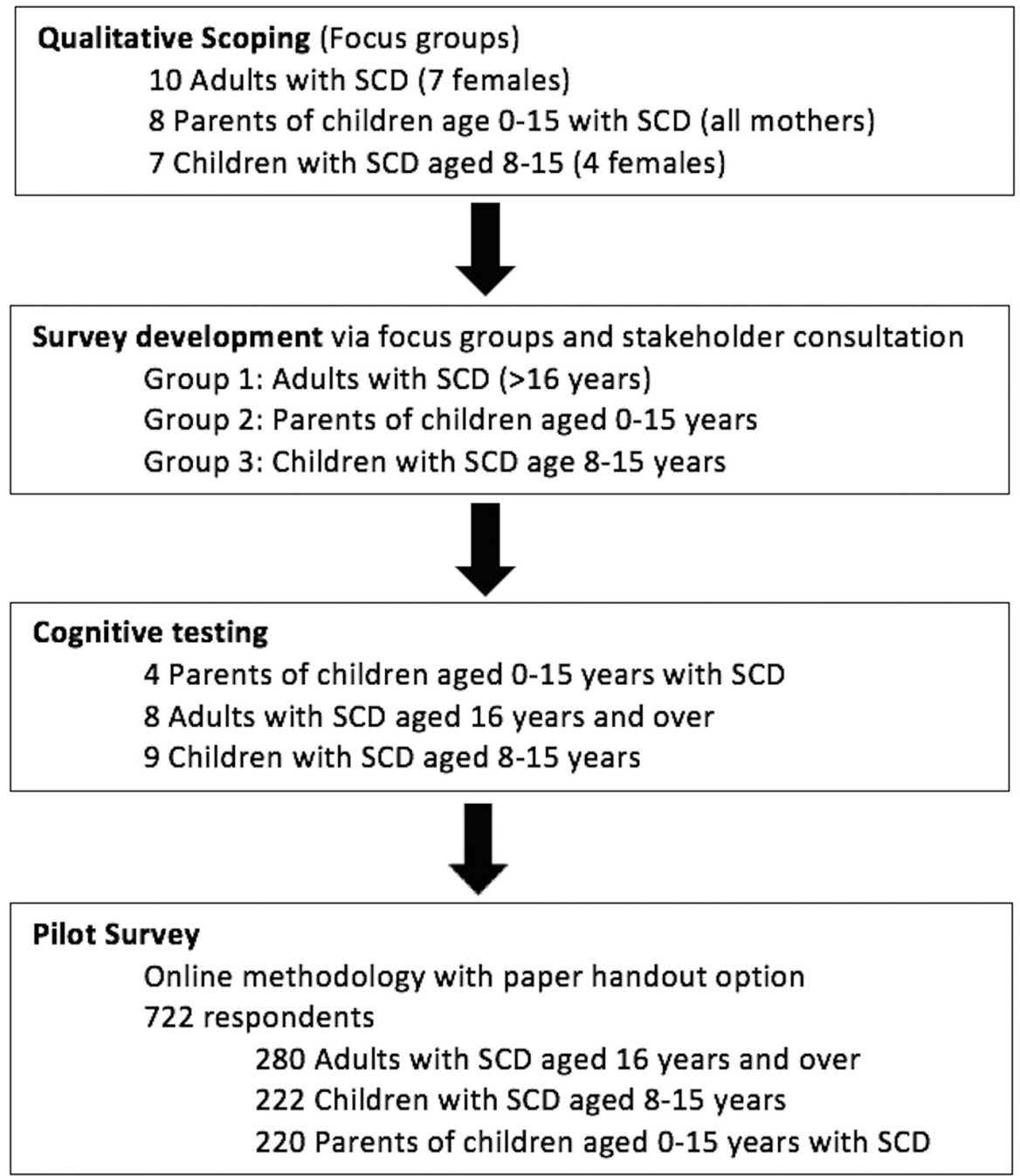

Figure 1 Study design and methodology. SCD, sickle cell disease.

structure of the questionnaires by a nationwide pilot survey (figure 1).

\section{Qualitative scoping}

Three focus groups were conducted with those affected by SCD children aged 8-15, adults aged 16 and over and carers of children aged $0-16$. Findings from the focus groups highlighted what was important to patients with SCD and their families in terms of the healthcare they receive, and what their priorities were. Findings informed the development of three SCD-specific PREMs, one for each patient/carer group.

\section{Cognitive testing}

The questionnaires were cognitively tested using face-to-face interviews on patients and carers to assess question comprehension, clarity of content and layout and to ensure that the response options adequately reflected the experiences of respondents.

\section{Pilot/survey implementation}

Following cognitive testing, a pilot was undertaken to trial data collection, further assess validity of the questionnaire data and to facilitate understanding of SCD patient and carer experiences of care in the UK. Responses were obtained by face-to-face encounters in SCD clinics or via an online web link. The pilot survey was conducted in 2015 over 6 months.
Survey fieldwork remained open until at least 200 completed responses per survey version were received. This target was set to achieve sufficiently precise estimates for later validation statistics.

Analysis and survey validation

Following closure of the survey fieldwork, data were extracted and analysed using the statistical software SPSS (V.22). Frequency tables were produced and problem scores were calculated for performance-related questions. Missing responses were not included in the analysis.

\section{Ethical considerations}

This study was classified as service evaluation according to the Health Research Authority definition ${ }^{10}$ and did not require review by an NHS Research Ethics Committee. However, all activities conformed to the Market Research Society's Code of Practice, including obtaining informed consent for focus group and cognitive interview participation.

\section{RESULTS}

Focus groups

Eight to 11 participants attended each focus group. See table 1 for key themes arising from these sessions, which informed the survey development. 
Table 1 Sickle cell focus groups: summary of findings

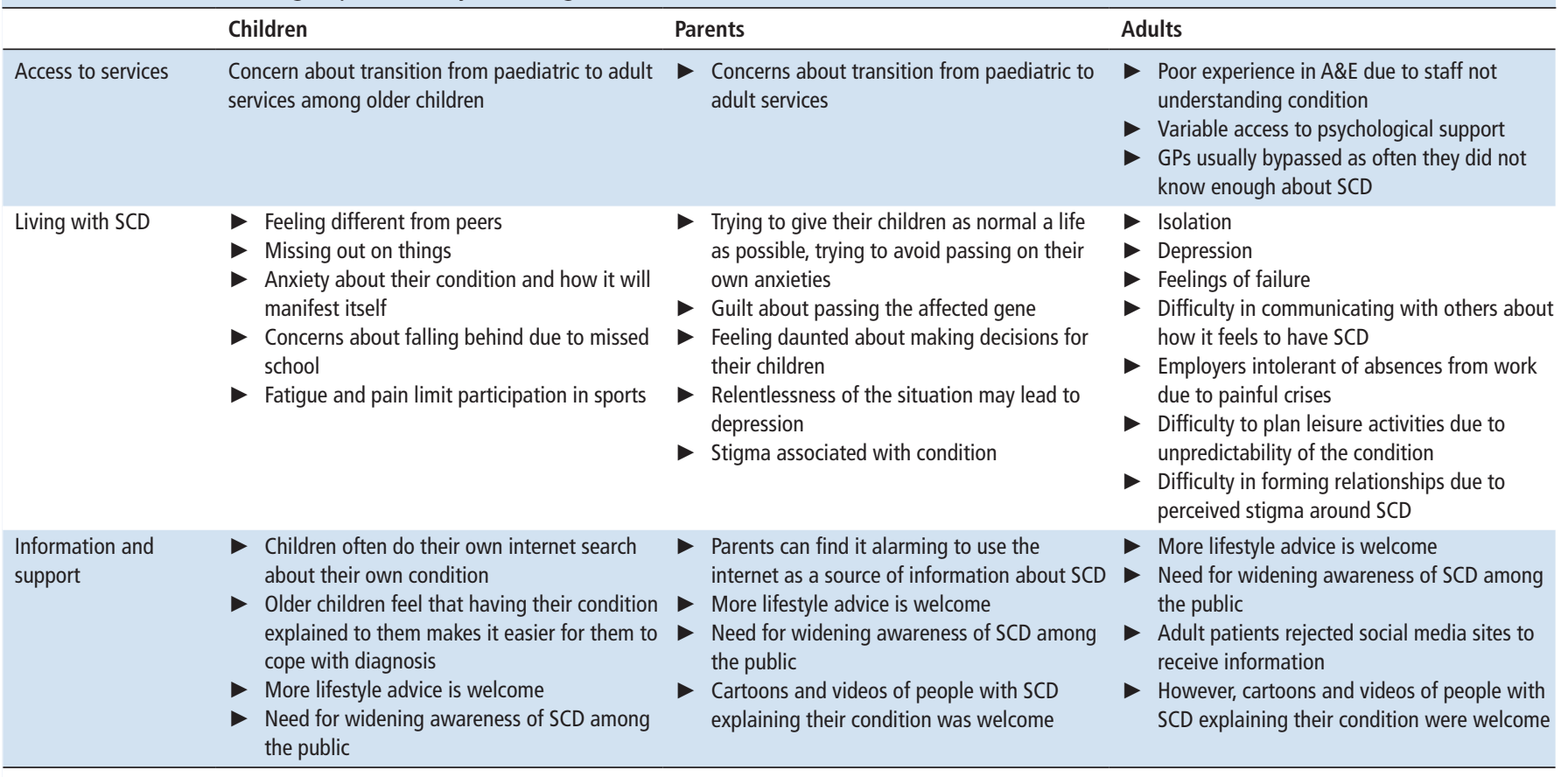

$A \& E$, Accident and Emergency; GP, general practitioner; SCD, sickle cell disease.

\section{Survey development}

Themes from focus group discussions informed the development of three PREM questionnaires following stakeholder engagement. The draft questionnaires were then cognitively tested with their respective target populations.

\section{Cognitive testing}

A total of 21 participants (four parents, eight adults and nine children) took part in the cognitive testing of the questionnaires, in three iterative rounds, following which several amendments were made to improve comprehension, response options and overall format. See online supplementary table 1 for a summary of changes.

\section{Final pilot questionnaires}

The final questionnaires covered the following areas:

- Access to advice and support.

- Information.

- Experiences of urgent care, hospital ward admission and outpatient clinic appointments.

- Communication with staff.

- Pain relief.

- Involvement in care and self-management of SCD.

\section{Pilot survey}

A total of 722 responses were obtained. Of these, $36 \%$ responses concerned children aged $9-15(\mathrm{n}=276), 32 \%$ from adults aged 20 and over $(n=226)$ and $4 \%(n=31)$ responses were from adults aged $16-20$.

\section{SURVEY RESULTS}

\section{Planned versus emergency care}

Experience of care in planned settings, mostly provided by specialist haematology services, was more positive compared with emergency care settings in several aspects. While 76\% $(\mathrm{n}=454)$ indicated that healthcare professionals (HCP) in a planned healthcare setting 'definitely knew enough about SCD', only $45 \%(n=102)$ thought so in the emergency care setting.

\section{Pain relief}

An important aspect of care for a patient with SCD is timely provision of pain relief. Remarkably, only $30 \%(n=26)$ of adults, $48 \%(n=28)$ of children and $42 \%(n=30)$ of parents felt that pain relief was provided to them in a timely manner in their most recent emergency healthcare episode.

\section{Information about SCD}

Many respondents felt that they 'definitely' received adequate information about SCD. This comprised $70 \%(\mathrm{n}=147)$ of parents, $51 \%(\mathrm{n}=111)$ of children and $60 \%(\mathrm{n}=163)$ adults. However, just $37 \%(\mathrm{n}=65)$ of parents and $27 \%(\mathrm{n}=51)$ of adult patients indicated that adequate information about the effect of this condition was being shared with schools and places of work by HCPs. Half $(51 \%, n=95)$ of children agreed the same.

Information regarding treatment options was also lacking in two-thirds of the individuals surveyed. This was particularly marked among adults, where just under a quarter received enough information about treatment options. Sixty-two per cent $(n=415)$ of respondents had enough information about coping with pain, 31\% $(\mathrm{n}=208)$ had some, but not enough and $7 \%$ $(n=49)$ had very little or no information about coping with pain. Furthermore, only $14 \%(n=73)$ of those surveyed felt that their friends and colleagues knew enough about the condition.

\section{Support}

Of those who wished to receive support from other users, just under a third had no information on how to access it. Of those who needed it, $45 \%(n=143)$ of parents and adults had received some form of help and input from psychological services. Nearly $90 \%(n=177)$ of children felt that they received sufficient help to cope with their condition. Less than a third of adults $(29 \%$, $\mathrm{n}=76)$ and around $60 \%$ of parents $(57 \%, \mathrm{n}=117)$ and children 


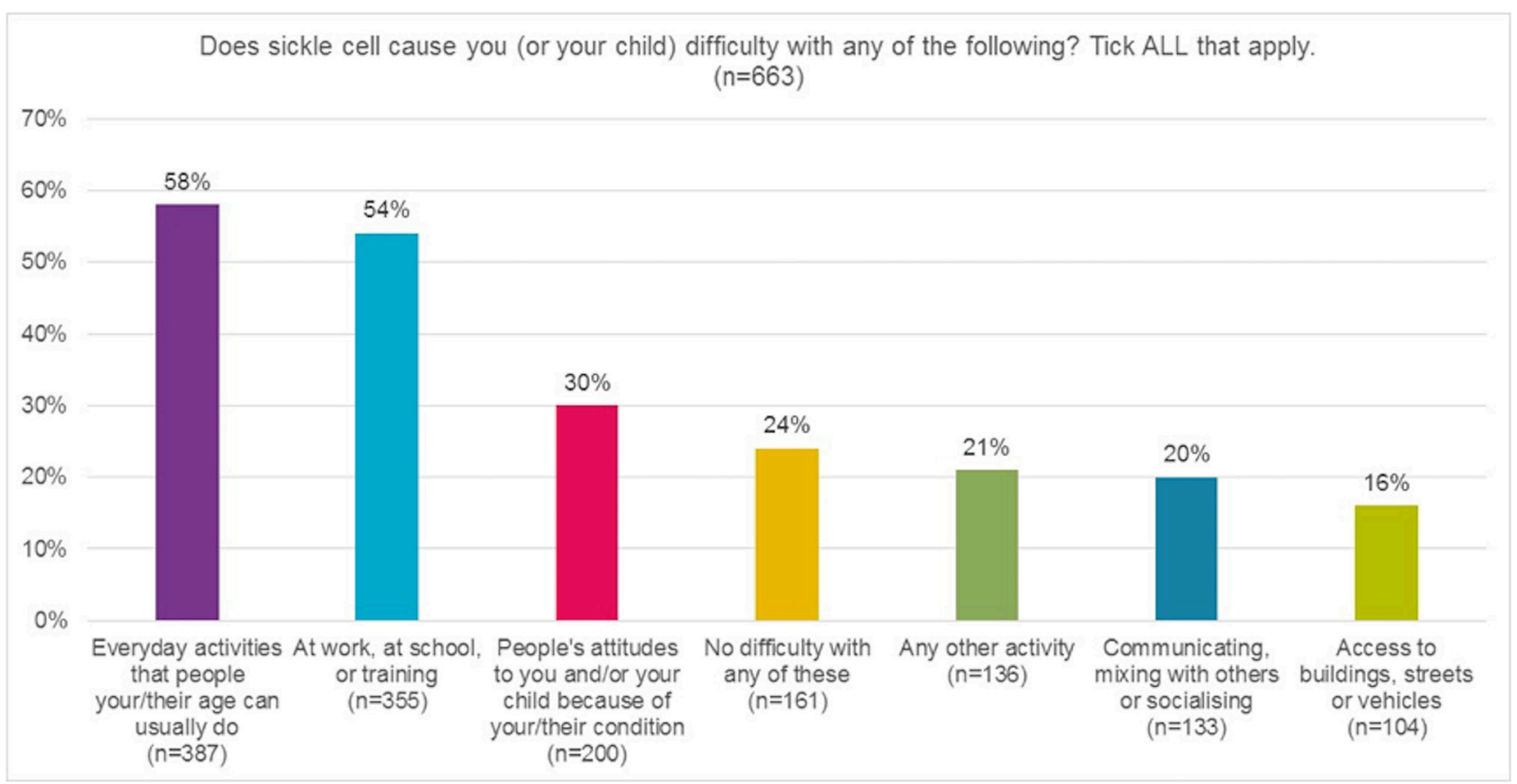

Figure 2 Impact of sickle cell disease on daily life.

$(61 \%, n=126)$ felt that they were looked after very well by HCPs.

\section{Living with SCD}

Figure 2 illustrates the impact of the condition on everyday life, as reported by the survey respondents, highlighting the debility that this condition imposes on affected individuals. Respondents were asked to describe in three words how living with sickle cell disorder made them or their child feel. Responses are displayed in the 'word cloud', as illustrated in online supplementary figure 1.

\section{Adolescent and young adults}

Respondents aged 16-20 years reported poorer experience of care than other ages in certain domains, including whether the ward they stayed on during a recent hospital admission was suitable for their age; whether they have enough information about when and how to use medications; and whether they have enough information about coping with pain. All of these differences were statistically significant-see table 2 for full details.

\section{Problem scores}

Picker problem scores were calculated for each question in the survey that measured experience. Here, response options that

Table 2 Differences in survey responses between adolescents/ young adults and other ages

\begin{tabular}{llll}
\hline & $\begin{array}{l}16-20 \text { year- } \\
\text { olds, \% (n) }\end{array}$ & $\begin{array}{l}\text { All other } \\
\text { ages, \% (n) }\end{array}$ & $\begin{array}{l}\mathbf{P} \text { values } \\
\left(\mathbf{X}^{2}\right)\end{array}$ \\
\hline $\begin{array}{l}\text { Ward was not suitable for age } \\
\text { group. }\end{array}$ & $74(14)$ & $39(161)$ & $0.003^{*}(8.8848)$ \\
$\begin{array}{l}\text { Did not have enough information } \\
\text { about when and how to use } \\
\text { medication(s). }\end{array}$ & $36(10)$ & $18(115)$ & $0.021^{*}(5.335)$ \\
$\begin{array}{l}\text { Did not have enough information } \\
\text { about coping with pain. }\end{array}$ & $17(5)$ & $7(44)$ & $0.043^{*}(4.083)$ \\
\hline
\end{tabular}

*The $\mathrm{X}^{2}$ statistic is significant at the 0.05 level. indicate a suboptimal experience are coded as a 'problem'. Such problem scores were created for each performance-related question to indicate where there is room for improvement in care delivery. Higher scores indicate a poorer self-report of care experience, highlighting potential areas for service development and improvement. See figure 3 for problem scores related to planned/ specialist-led, emergency and hospital care. For problem scores relating to information, support and management of SCD, see online supplementary figures $2-4$.

\section{Validation}

Statistical validation was conducted on every question to explore construct validity. An examination of interitem polychoric correlations indicated that every item in the questionnaire served to explore a distinct aspect of patient experience, with minimal overlap or redundancy, see online supplementary table 2 for details. Overall, the conclusion from the validation analysis was that all questions functioned well and could be retained in the final tools.

\section{Dissemination of survey results}

Findings from this national patient survey were published as a formal report. ${ }^{11}$ The key messages were summarised in an infographic. ${ }^{12}$ Specific findings for the poorer experiences reported by $16-20$ year-olds were summarised in individual Twitter cards (online supplementary figure 5). These outputs were necessary for communicating key findings to respondents, their families, HCPs and the public and were deemed by the project team to be a necessary ethical component of the work.

\section{DISCUSSION}

To our knowledge, this is the first ever report of a UK-wide survey for SCD that was developed and piloted as a tool to measure health and lived experience of patients and their parents/carers.

In the current study, several areas of care provision for patients with SCD have been highlighted to be inadequate, particularly in emergency care settings. The perceived lack of knowledge among acute, non-specialist care providers regarding SCD has 


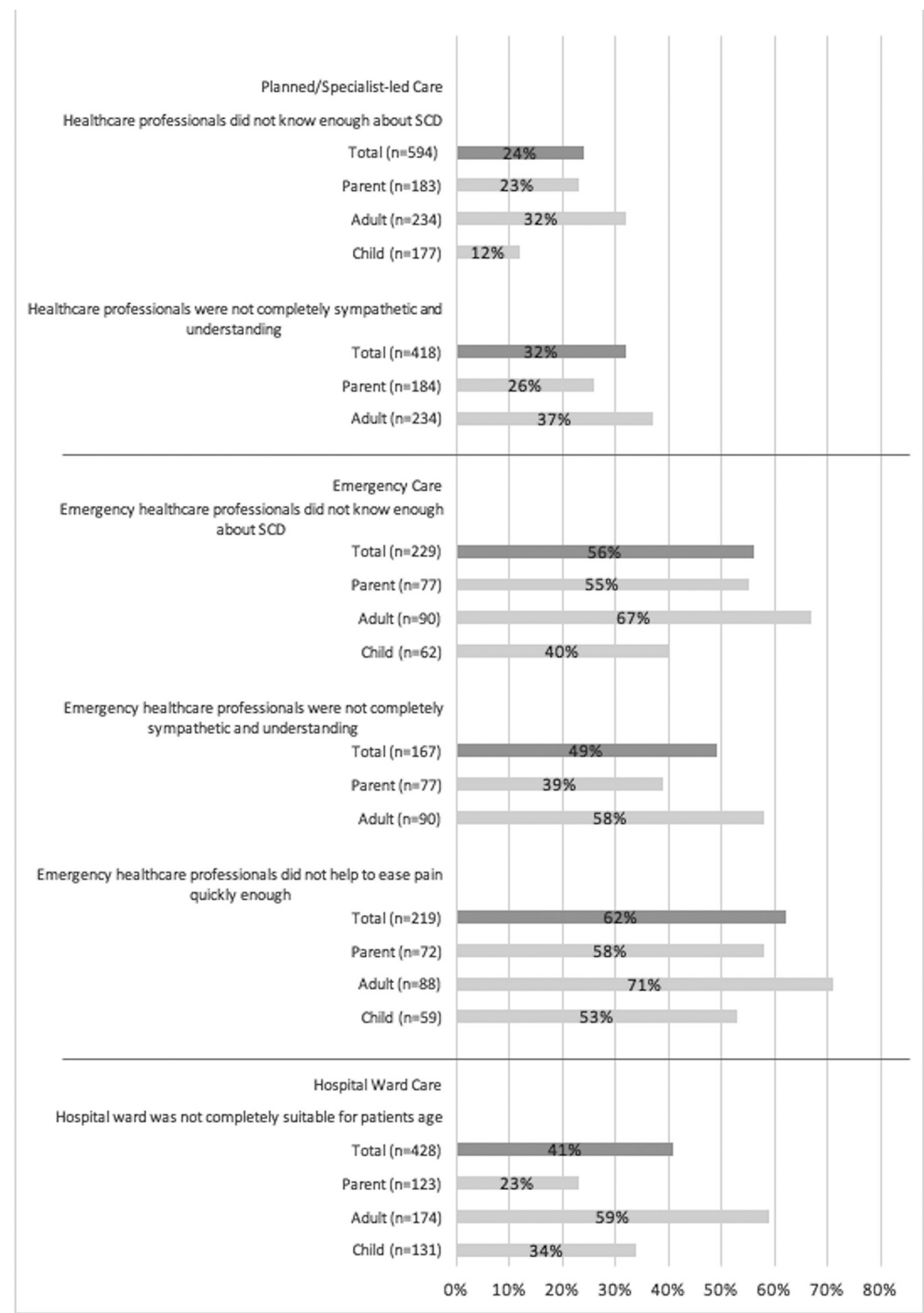

Higher problem scores indicate a greater problem/ more room for improvement

Figure 3 Problem scores for planned/specialist-led, emergency and hospital care. SCD, sickle cell disease.

also been highlighted in previous studies. ${ }^{13}$ Many users felt that pain relief was not being provided in a timely manner when presenting to emergency departments, despite national guidance indicating that pain relief should be provided within $30 \mathrm{~min}$ of presentation in an acute care setting. ${ }^{14}$

Another widespread issue highlighted in the survey was the lack of knowledge and information among the wider population regarding SCD. This has relevance in the UK context where SCD remains one of the most common severe inherited conditions among newborns, indicating the need for more awareness initiatives for the public.

Patient experience among adolescents and young adults was significantly lower than any other age groups across some of the surveyed domains, a finding that is consistent with other studies. ${ }^{15}$ This is of particular concern, as studies have indicated that the risk of increased mortality and morbidity in SCD occurs among young people if a robust care pathway was not in place. ${ }^{16} 17$ However, in this study, far fewer surveys were completed by respondents aged 16-20 years compared with adults, risking the introduction of non-response bias. Non-response among young adults is a common finding across surveys. The youngest age group has consistently low response rates across national adult surveys, as demonstrated in the 2016 UK national inpatient survey. ${ }^{18}$ Our survey was not designed to address non-response bias, as the primary aim was to undertake a pilot survey to compute validation statistics. 
Timely and effective access to primary care in the management of SCD is a controversial subject in the UK. While the pivotal role of primary care services in the overall management of SCD is acknowledged, systems-level barriers preclude the effective utilisation of such services at a practical level. ${ }^{19}{ }^{20}$ Findings from this survey mirrored previous reports of overall poor experience in the primary care setting, leading to families preferring to seek emergency hospital care instead. ${ }^{21}$

Data derived from large UK inpatient surveys indicate that individuals with one or more long-term conditions have significantly poorer experiences of hospital care compared with those with none. ${ }^{22} 23$ This finding was also mirrored in the recent report of the National Children's 2014 Survey which found poorer experiences of care for those with a long-term health condition. ${ }^{24}$

This survey provides a unique insight into the lived and care experiences of individuals with SCD, using a series of PREMs that are tailored to the healthcare needs of this population. This condition is often described as 'hidden', owing to the lack of overt physical characteristics, ${ }^{25}$ but our survey has demonstrated the huge burden of debility associated with SCD. As $99 \%$ of children with SCD in the UK will survive through to adulthood, ${ }^{26}$ these data provide valuable information for healthcare service planning. The PREMs are available for those providing healthcare to patients with sickle cell to use for understanding patient experiences of care locally, and informing where there might be room for improvement in care delivery.

\section{CONCLUSION}

This study has demonstrated for the first time a national view of healthcare experience of individuals with SCD and their carers. In future, the PREMs will be available to eligible care providers to obtain feedback, and serve as a unique tool with good validity evidence that will help inform future delivery, design and commissioning of services for people with SCD.

Acknowledgements The authors thank the patients with SCD and their carers who have completed the surveys and/or taken part in the focus groups and cognitive testing exercises. The authors acknowledge the help from SCD service providers in the UK who have encouraged patients to participate in the surveys.

Contributors SC, JOW, GS and AT designed the study. CM, AO, PO, AJW and JT assisted in data collection. AT, HH and CW undertook focus group interviews cognitive testing and questionnaire design. SS undertook postpilot validation statistics. All authors reviewed the manuscript.

Funding This article presents independent research supported by the National Institute for Health Research (NIHR) under the Collaborations for Leadership in Applied Health Research and Care (CLAHRC) programme for North West London.

Disclaimer The views expressed in this publication are those of the author(s) and not necessarily those of the NHS, the NIHR or the Department of Health and Social Care.

Competing interests None declared.

Patient consent Not required.

Provenance and peer review Not commissioned; externally peer reviewed.

Data sharing statement The authors confirm that all data underlying the findings described in their manuscript are fully available without restriction.

Open access This is an open access article distributed in accordance with the Creative Commons Attribution Non Commercial (CC BY-NC 4.0) license, which permits others to distribute, remix, adapt, build upon this work non-commercially, and license their derivative works on different terms, provided the original work is properly cited, appropriate credit is given, any changes made indicated, and the use is non-commercial. See: http://creativecommons.org/licenses/by-nc/4.0/.

\section{REFERENCES}

1 Piel FB, Steinberg MH, Rees DC. Sickle cell disease. N Engl J Med 2017;376:1561-73.

2 National Sickle Cell and Thalassaemia Screening Programme. Data Report 2013/14-Trends and performance analysis London: Public Health England. 2015 https://www.gov.uk/government/uploads/system/uploads/attachment_data/file/ 510622/SCT_data_report_final_1.0.pdf.

3 National Haemoglobinopathy Register. NHR information service patient number by centre and diagnosis: national haemoglobinpathy register. 2016 http://www.nhr.nhs. uk/wp-content/uploads/2016/05/NumberPatientsByCentre.pdf.

4 Bediako SM, Lanzkron S, Diener-West M, et al. The Measure of Sickle Cell Stigma: Initial findings from the Improving Patient Outcomes through Respect and Trust study. $J$ Health Psychol 2016:21:808-20.

5 Gupta M, Msambichaka L, Ballas SK, et al. Morphine for the treatment of pain in sickle cell disease. ScientificWorldJournal 2015:2015:1-10.

6 Aljuburi G, Laverty AA, Green SA, et al. Socio-economic deprivation and risk of emergency readmission and inpatient mortality in people with sickle cell disease in England: observational study. J Public Health 2013;35:510-7.

7 Department of Health. High quality care for all, NHS Next stage review, London DOH 2008. London: Department of Health UK, 2008. Contract No.: 28/07/2017.

8 Black N, Jenkinson C. Measuring patients' experiences and outcomes. BMJ 2009;339:b2495.

9 Doyle C, Lennox L, Bell D. A systematic review of evidence on the links between patient experience and clinical safety and effectiveness. BMJ Open 2013;3:e001570.

10 Health Research Authority. Defining research: Health Research Authority. 2016 http:// www.hra.nhs.uk/documents/2016/06/defining-research.pdf.

11 Tallett A, Witiwicki C. Piloting a new Patient Reported Experience Measure- Report of the Findings: Picker Institute Europe. 2015 http://www.pickereurope.org/wp-content/ uploads/2016/06/Sickle-Cell-Pilot-Report.pdf.

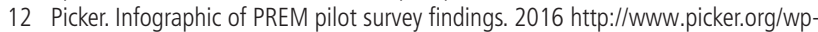
content/uploads/2017/02/P2745_Sickle-Cell_Main-Infographic_170517-1.pdf

13 Maxwell K, Streetly A, Bevan D. Experiences of hospital care and treatment seeking for pain from sickle cell disease: qualitative study. BMJ 1999:318:1585-90.

14 National Institute of Clinical Excellence. Sickle Cell Disease- Managing Acute Painful Episodes in Hospital. London: National Institute of Clinical Excellence, 2012.

15 Hargreaves DS, Greaves F, Levay C, et al. Comparison of Health Care Experience and Access Between Young and Older Adults in 11 High-Income Countries. J Adolesc Health 2015;57:413-20.

16 Sawicki GS, Garvey KC, Toomey SL, et al. Development and Validation of the Adolescent Assessment of Preparation for Transition: A Novel Patient Experience Measure. J Adolesc Health 2015;57:282-7.

17 de Montalembert M, Guitton C. Transition from paediatric to adult care for patients with sickle cell disease. Br J Haematol 2014;164:630-5.

18 Care Quality Commission. 2016 Adult Inpatient Survey: Quality and Methodology Report, 2016.

19 Jacob E, Childress C, Nathanson JD. Barriers to care and quality of primary care services in children with sickle cell disease. J Adv Nurs 2016;72:1417-29.

20 Aljuburi G, Okoye 0, Majeed A, et al. Views of patients about sickle cell disease management in primary care: a questionnaire-based pilot study. JRSM Short Rep 2012;3:78.

21 Aljuburi G, Phekoo KJ, Okoye NO, et al. Patients' views on improving sickle cell disease management in primary care: focus group discussion. JRSM Short Rep 2012:3:1-7.

22 Hewitson P, Skew A, Graham C, et al. People with limiting long-term conditions report poorer experiences and more problems with hospital care. BMC Health Serv Res 2014; $14: 33$

23 Gore C, Griffin R, Rothenberg T, et al. New patient-reported experience measure for children with allergic disease: development, validation and results from integrated care. Arch Dis Child 2016;101:935-43.

24 Care Quality Commission. Children and young people's inpatinet and day case survey 2014. 2015 http://www.cqc.org.uk/sites/default/files/20150630_cypsurvey_ keyfindings.pdf.

25 Dyson SM, Atkin K, Culley LA, et al. Disclosure and sickle cell disorder: a mixed methods study of the young person with sickle cell at school. Soc Sci Med 2010;70:2036-44.

26 Telfer P, Coen P, Chakravorty S, et al. Clinical outcomes in children with sickle cell disease living in England: a neonatal cohort in East London. Haematologica 2007;92:905-12. 